\title{
Sources and Cycling of Germanium Isotopes in Aquatic Systems
}

\author{
O. J. ROUXEL ${ }^{1 *}$, J. J. BARONAS ${ }^{2}$
}

${ }^{1}$ IFREMER, Marine Géosciences Division, Centre de Brest, 29280 Plouzané, France (* correspondance : orouxel@ifremer.fr)

${ }^{2}$ Dept. of Earth Sciences, University of Cambridge, Cambridge CB2 3EQ, UK (jotautas.baronas@gmail.com)

Although Germanium (Ge) has no known biological use, dissolved inorganic Ge concentrations in seawater display a correlation with dissolved silica that is remarkably consistent across the world's oceans, underlying its potential as a complementary tracer for marine silicon cycling. The interest for tracing Ge cycle in aquatic systems derives from the close association between $\mathrm{Ge}$ and $\mathrm{Si}$ global biogeochemical cycles, yet at the same time major Si sources to the ocean (rivers and hydrothermal sources) have dramatically different $\mathrm{Ge} / \mathrm{Si}$ ratios that may be recorded in the sedimentary record as a proxy for climate-related changes in weathering regimes, and continental vs. hydrothermal geochemical fluxes.

Motivated by the promise of the Ge/Si proxy, we have recently explored the use of $\mathrm{Ge}$ isotope ratios [defined as $\delta^{74 / 70} \mathrm{Ge}=1000 *\left({ }^{74} \mathrm{Ge} /{ }^{70} \mathrm{Ge}_{\text {sample }} /{ }^{74} \mathrm{Ge} /{ }^{70} \mathrm{Ge}\right.$ NIST3120a -1$\left.)\right]$ as an independant tracer to unravel (1) the far-field impact of hydrothermal venting on the geochemical budget of $\mathrm{Ge}$ in seawater and marine sediments; (2) the mechanisms of biological Ge uptake in the oceans; (3) the importance of boundary exchange on continental margin altering the global Ge oceanic budget [1-6].

Capitalizing on these reconnaissance studies, we will discuss the potential use of Ge isotopes as tracers of chemical weathering processes, both in surficial environments (e.g. glacial and tropical watersheds) and subseafloor oceanic basement. This approach will lead to a comprehensive geochemical understanding of $\mathrm{Ge}$ isotope systematics in modern environments, opening the prospect of using $\mathrm{Ge}$ isotopes as new paleoenvironmental proxies, from glacialinterglacial timescales to the Precambrian.

[1] Escoube et al. (2015) GCA 167, 93-112. [2] Baronas et al. (2017) GCA 203, 265-283. [3] Rouxel and Luais (2017) Reviews in Mineral. \& Geochem., 82, 601-656. [4] Guillermic et al. (2017) GCA 212, 99-118. [5] Baronas et al. (2019) Front. Earth Sci. 7, 00162. [6] Baronas et al. (2018) EPSL 503, 194-215. 